\title{
The Comparative Effect of Air Pollution Caused by Greenhouse Gases Emissions on the Health of Men and Women in the Upper Middle- Income Countries
}

\author{
Seyed Mohammad Javad Razmi ${ }^{1}$ \& Tayyebe Azodi ${ }^{1}$ \\ ${ }^{1}$ Ferdowsi University of Mashhad, Iran \\ Correspondence: Seyed Mohammad Javad Razmi, Iran, Mashhad, Faculty of Economics and Administrative \\ Sciences, Ferdowsi University, Mashhad, Iran. Tel: 98-051-3880-5379. E-mail: mjrazmi@um.ac.ir
}

Received: April 13, 2018

Accepted: June 20, 2018

Online Published: July 15, 2018

doi:10.5539/mas.v12n8p19

URL: https://doi.org/10.5539/mas.v12n8p19

The research is financed by Ferdowsi University of Mashhad.

\begin{abstract}
Greenhouse gas emissions and air pollution is a heterogeneous, complex mixture of gases, liquids and particulate matter and one of the major problems in the world which threatens the health of individuals and although this factor alone does not lead to death, it is very dangerous by affecting the progress and the progress speed of some diseases. Given the importance of health, in this paper, the effect of greenhouse gas pollution will be examined on the health of men and women in 33 upper middle-income countries from 2000 to 2016 in the form of panel data. The research results show that during the period studied, greenhouse gas pollution had a negative and significant effect on the health of men and women in the countries studied, but its effect on women's health was more than that of men.
\end{abstract}

Keywords: air pollution, Greenhouse Gas Emissions, Health, Panel Data Model

JEL Classifications: I10, Q01, Q53

\section{Introduction}

Air pollution include a heterogeneous mixture of solid and liquid particles suspended in air that varies continuously in size and chemical composition in space and time (Brook, Robert D., et al. 2004) And process that introduces different pollutants into the atmosphere that reason harm to humans, other living organisms, and the natural environment (Kinney, 2008; Brauer et al., 2012. Kim et al. 2015). These pollutants are associated with increased hospitalization (Poloniecki, Jan D., et al.1997) and mortality due to cardiovascular disease (Pope III, C. Arden, et al. 2002, Pope, C. Arden, et al. 2004, Samet, Jonathan M., et al. 2000) especially in persons with congestive heart failure, frequent arrhythmias, or both (Mann, Jennifer K., et al. 2002).

Air pollution has deleterious effects on both physical and mental health. (Fotourehchi, 2016) More than two million deaths per year are the direct result of air pollution through damage to the lungs and respiratory system (Shah et al. 2013). they were strongly associated with the industrial structure and development stage of a country. the economic recession period could function as a perfect timing for the reduction in air pollution level and the mortality induced by pollution (Chen et al. 2016).

Particulate matter (PM) is a key indicator of air pollution brought into the air by a variety of natural and human activities.

Carbon dioxide is responsible to $\% 58.8$ of greenhouse gas emission that has adversely influences on health status, it is toxic to the heart and causes diminished contractile force. ( Muchopadhyay and Forssell, 2005, Davidson, 2003)

great in number scientific studies have explained particle exposure as the source of various health problems including premature death in people with lung disease and decreased lung function, irregular heartbeat, nonfatal heart attacks, aggravated pursiness, and increased respiratory symptoms such as coughing, irritation of the airways, or difficulty breathing (Atkinson et al. 2010; Cadelis et al. 2014; Correia et al. 2013; Fang et al. 2013; Meister et 
al. 2012)

\section{Literature Review}

Fang et al. (2013) estimated that about $5 \%$ of lung cancer deaths and $3 \%$ of cardiopulmonary are ascribable to Particulate matter globally. Correia et al. (2013) suggested a possible relation between decrease in fine particulate matter and improved life expectancy based on data collected from 545 counties in the U.S. During the 2000- 2007. Their studies represent that a decline of $10 \mu \mathrm{g} \mathrm{m}-3$ of PM2.5 should have led to an increase of life expectancy by 0.35 years on average. Cao et al. (2011) perform a study to investigate the association between air pollution and mortality in 70,947 middle-aged men and women of the China National Hypertension Survey and its followup study.

Substantial associations were found between air pollution levels and mortality from lung cancer and cardiopulmonary diseases. Krewski (2009) indicate that Exposure to PM2.5 reduce the life expectancy of the population by about 8.6 months on average.

The similar research was estimateed reflect the very significant role air pollution plays in cardiovascular illness and death. More and more, evidence demonstrating the linkages between ambient air pollution and the cardiovascular disease risk is becoming available, including studies from highly polluted areas.

\section{Materials and Methodology}

In this research an empirical model was used to examine the comparative effect of air pollution caused by greenhouse gases on the health indicators of Men and Women as below:

\begin{tabular}{|c|c|}
\hline LMRM $=\alpha_{\mathrm{i}}+\beta_{1} \mathrm{LPM} 2.5_{\text {it }}+\beta_{2} \mathrm{LCO}_{2}$ it $+\beta_{3} \mathrm{OTG}_{\mathrm{it}}+\beta_{4} \mathrm{SCM}_{\text {it }}+\mathrm{U}_{\mathrm{it}}$ & (1) \\
\hline $\mathrm{LMRW}=\alpha_{\mathrm{i}}+\beta_{1} \mathrm{LPM} 2.5_{\text {it }}+\beta_{2} \mathrm{LCO}_{2}$ it $+\beta_{3} \mathrm{OTG}_{\mathrm{it}}+\beta_{4} \mathrm{SCW}_{\mathrm{it}}+\mathrm{U}_{\mathrm{it}}$ & (2) \\
\hline
\end{tabular}

$\mathrm{i}=1,2, \ldots, \mathrm{N}$ and $\mathrm{t}=1,2, \ldots, \mathrm{T}$ denote number of countries $(\mathrm{i}=1,2, \ldots, 33(\mathrm{~N}))$ and time period $(\mathrm{t}=2000,2001, \ldots$. $2016(T))$, respectively. $\alpha$ are constants and $\beta 1, \beta 2, \beta 3, \beta 4$ are coefficients. $U$ is the error term that are normally distributed with zero mean and homoscedastic variance $U_{i t} \square d\left(0, \sigma_{\mathcal{E}}^{2}\right)$. All the variables in Eq. $(1,2)$ are in logarithmic form. The main health status proxy variables in the both equations are Adult mortality rate men (MRM) and women (MRW), is the probability of dying between the ages of 15 and 60-that is, the probability of a 15-yearold men (women) dying before reaching age 60, if subject to age-specific mortality rates of the specified year between those ages.

There are three different air pollution proxy variables that their data are available for the analysis: 1. Carbon dioxide $\mathrm{CO} 2$ emissions (metric tons per capita) that are mostly stemming from the burning of fossil fuel and manufacture of cements that through releasing toxic substance into environment lead to negative health effects. 2 . Particulate matter PM2.5 country level concentrations (micrograms per cubic meter). Particulate matter concentrations refer to fine suspended particulates less than 2.5 microns in diameter that are capable of penetrating deep into the respiratory tract and causing significant health damage. 3. Other greenhouse gas (HFC, PFC and SF6) emissions are by-product emissions of hydro fluoro carbons, per fluoro carbons, and sulfur hexafluoride (OTG). In the both equations social factors such as education levels are represented for the estimation and school enrollment, tertiary (\% gross), respectively. School enrollment, tertiary (\% gross) of men in equation 1 (SCM) and women in equation 2 (SCW) are defined as total enrollment in tertiary educations, regardless of age, expressed as a percentage of population of official tertiary education age. It is seen that, levels of Gross enrollment ratio, significantly influence on $\mathrm{CO} 2$ emission and PM2.5 and other gas concentration of the countries (world Bank, 2016).

For this paper, data collected from 33 countries upper middle-income level in the period 2000-2016.This data obtained from World Bank and countries are Contains:

Albania, Algeria, Argentina, Azerbaijan, Belarus, Belize, Botswana, Brazil, Bulgaria, Colombia, Costa Rica, Croatia, Dominican Republic, Ecuador, Equatorial Guinea, Fiji, Guyana, Iran Islamic Rep, Jamaica, Kazakhstan, Lebanon, Macedonia, Malaysia, Mexico, Namibia, Panama, Paraguay, Peru, Romania, South Africa, Suriname, Thailand, Venezuela.

In this study we estimate the model by using panel data method. For using panel data model particular test method are used which will be discussed in this section. Before discussion about estimation and model analysis, it is necessary that why this study try to use the panel data method. In other words, are the countries -which are going 
to be studied- homogeneous or not? If the countries are homogeneous Pool Data method can be easily used by ordinary least squares otherwise, the necessity of using panel data is required. In other words, based on statistical concept we have:

$Y_{i}=Z_{i} \delta+U_{i}$ Conditional Model

$Y_{i}=Z_{i} \delta_{i}+\mathrm{U}_{\mathrm{i}}$ Non-Conditional Model

$i=1,2, \ldots, N$

The statistics for testing the hypothesis is as follows:

$$
\begin{gathered}
F_{(N-1, N T-N-K)}=\frac{\left(R_{U R}^{2}-R_{R}^{2}\right) /(N-1)}{\left(1-R_{U R}^{2}\right) /(N T-N} \\
-K)
\end{gathered}
$$

Which $N$ represents the number of country, $K$ the number of explanatory variables, $T$ the number of observations over the time. In this test (which is called as significance effects of group test) when null hypothesis rejected, using of panel data is required. For decision about using of Fixed Effects method or Random Effects method, it must be considered that fixed effect method is usually used when total population is considered and if samples selected from big population, random effect method will be better method (Baltagi, 2005, 2008).

Hausman Test is used for determining the method of estimation in panel data approach which its statistic is $(\mathrm{H})$ with $\chi^{2}$ distribution with $K$ degree freedom (number of explanatory variables). If the null hypothesis rejected in the first test, the second test (Hausman Test) for the method of estimation in panel data methods will be used. In the Fixed Effects method, time aspect is not considered and only the effects which belong to each section of the time will be consider as individual effects. In the Random Effects method, time aspect is considered and the effects which belong to each section of the time will be consider as individual effects in the model. Hausman test statistic is as follows:

$$
\mathrm{H}=\frac{\dot{\beta}_{\mathrm{FE}}-\dot{\beta}_{\mathrm{RE}(\mathrm{GLS})}}{\operatorname{VAR}\left(\dot{\beta}_{\mathrm{FE}}\right)-\operatorname{VAR}\left(\dot{\beta}_{\mathrm{RE}(\mathrm{GLS})}\right)}
$$

This test is hypothesis testing of uncorrelated individual effects and the explanatory variables which based on this test the generalized least squares estimation (GLS) under the $\mathrm{H}_{0}$ hypothesis is consistent and under $\mathrm{H}_{1}$ hypothesis is inconsistent. These hypothesis are as follows:

$\mathrm{H}_{0}: \mathrm{E}\left(\mathrm{u}_{\mathrm{it}} / \mathrm{x}_{\mathrm{it}}\right)=0$

$\mathrm{H}_{1}: \mathrm{E}\left(\mathrm{u}_{\mathrm{it}} / \mathrm{x}_{\mathrm{it}}\right) \neq 0$

The rejection of the null hypothesis implies that the test method is fixed effects (Baltagi, 2005, 2008).

Table 1.

Chow test results for men

\begin{tabular}{ccccc}
\hline $\begin{array}{c}\text { Fixed Effect } \\
\text { Test(Chow) }\end{array}$ & $\begin{array}{c}\text { Significance level } \\
\times 10^{-4}\end{array}$ & F degree freedom & Calculated F & Result \\
\hline Panel & $(0.0000)$ & $(29,68)$ & 209.24 & $\mathrm{H}_{0}$ is rejected \\
\hline \multicolumn{5}{c}{ Chow test results for women } \\
\hline $\begin{array}{c}\text { Fixed Effect } \\
\text { Pest(Chow) }\end{array}$ & $\begin{array}{c}\text { Significance level } \\
\times 10^{-4} \\
(0.0000)\end{array}$ & F degree freedom & Calculated F & Result \\
Panel & $(29,68)$ & 112.33 & $\mathrm{H}_{0}$ is rejected \\
\hline
\end{tabular}

Source: Research calculations.

Table 2.

Hausman test for men

$\begin{array}{lcccc}\text { Hausman Test } & \begin{array}{c}\text { Significance level } \\ \times 10^{-4}\end{array} & \begin{array}{c}\chi^{2} \text { degree } \\ \text { freedom }\end{array} & \text { Calculated } \chi^{2} & \text { Result }\end{array}$




\begin{tabular}{ccccc}
\hline Panel & 0.006( & 4 & 18.26 & $\mathrm{H}_{0}$ is rejected \\
\hline Hausman Test & $\begin{array}{c}\text { Significance level } \\
\times 10^{-4}\end{array}$ & $\begin{array}{c}\chi^{2} \text { degree } \\
\text { freedom }\end{array}$ & Calculated $\chi^{2}$ & Result \\
\hline Panel & ) 0.000( & 4 & 25.67 & $\mathrm{H}_{0}$ is rejected \\
\hline
\end{tabular}

Source: Research calculations.

Test results for both model indicate that a good model is panel data model with fixed effects.

Model Estimation Results:

Table 3 .

Model results of the regression model for men

\begin{tabular}{|c|c|c|c|c|c|c|c|}
\hline variable & & & & & & & F statistic \\
\hline Method & $\mathrm{C}$ & LPM2.5 & $\mathrm{LCO}_{2}$ & LOTG & LSCM & $R^{2}$ & \\
\hline \multirow{2}{*}{$\begin{array}{r}\text { Fixed } \\
\text { Effects } \\
\text { Model }\end{array}$} & 6.56 & 0.036 & $0.07 *$ & 0.01 & 0.32 & 0.84 & 272.6 \\
\hline & $(0.000)$ & $(0.48)$ & $(0.09)$ & $(0.000)$ & $(0.000)$ & & $(0.000)$ \\
\hline \multirow{2}{*}{\multicolumn{8}{|c|}{$\begin{array}{r}* \text { indicates significance at } 10 \% . \\
\text { Mod }\end{array}$}} \\
\hline & & & & & & & \\
\hline variable & & & & & & & F statistic \\
\hline Method & $\mathrm{C}$ & LPM2.5 & $\mathrm{LCO}_{2}$ & LOTG & LSCW & $R^{2}$ & \\
\hline \multirow{2}{*}{$\begin{array}{l}\text { Fixed } \\
\text { Effects } \\
\text { Model }\end{array}$} & 5.8 & 0.003 & 0.12 & 0.01 & -0.28 & \multirow[t]{2}{*}{0.78} & $\begin{array}{l}182.31 \\
(0000)\end{array}$ \\
\hline & $(0.000)$ & $(0.96)$ & $(0.01)$ & $(0.000)$ & $(0.000)$ & & $(0.000)$ \\
\hline
\end{tabular}

Source: Research calculations.

\section{Results}

As observed in Table (3), statistics value and probability level in the first model show that all coefficients, except PM2.5, are significant at $99 \%$ confidence level and carbon dioxide emissions, are significant at $90 \%$ confidence level. Particulate matter carbon dioxide emissions coefficient shows that, assuming other factors are constant, with an increase of 1 percent in Particulate matter carbon dioxide emissions, the mortality rate of men in the countries studied is $0.07 \%$, and in addition, assuming other factors are constant, with 1 percent increase in the emissions of other greenhouse gases (HFC, PFC and SF6), the mortality rate of men increases by 0.01 percent.

The statistics value and probability level in the second model show that all coefficients, except for Particulate matter PM2.5 coefficient, are significant at the 99\% confidence level. The carbon dioxide emission Coefficient shows that, assuming other factors are constant, with an increase of 1 percent in the carbon dioxide emissions, the mortality rate in women is 12 percent, and assuming other factors are constant, with 1 percent emission of other greenhouse gases (HFC, PFC and SF6), the mortality rate in women increases by 0.01 percent. In addition, indicating a good fit and the fact that the independent variables in the model's particles coefficient explain several percent of the dependent variable, the value of $R^{2}$ is 0.84 in the first model and 0.78 in the second model.

\section{Conclusions and Discussion}

Given the importance of health, this study aimed to investigate and compare the effects of air pollution from greenhouse gas emissions on the health of men and women in the upper middle-income countries including Iran. 
Using panel data in the period 2000-2016, this study was conducted in which mortality rate of women and men was used as a health indicator. It was expected that as men stay longer outside and therefore are more exposed to air pollution it has a more damaging effect on their health, while the results showed that although greenhouse gas emissions significantly increase the mortality rate of women and men, its impact on women's mortality is more. Therefore, it can be said that environmental pollution, especially air pollution, will have a more negative effect on women due to their hormonal changes, regardless of skin, digestive, cardiovascular, pulmonary diseases and cancers.

Given the sensitivity of women, especially pregnant women, and the fact that air pollution will cause negative effects such as cardiac abnormalities, decreased IQ and fetal weight loss, and thus it will have negative consequences for the health of next generation; while the identification of health problems, including the effects of air pollution, should be prioritized, and fundamental measures should be taken to reduce pollutants, how to deal with this phenomenon should be taught especially to pregnant women and mothers and accurate information should be provided to them so that they refrain from going outside in urban open spaces on the days in which the air is polluted and consider fluids and foods including antioxidants and iron in their own diet. In addition, generally the identification and control of the sources of air pollution, urbanization control, the development of urban green space, the prevention of natural resource degradation, strict control and monitoring of the centers of technical inspection of vehicles, the development of public transport fleet, culture building and the development of equipment for measuring air pollutants can be effective in reducing air pollution and its harmful effects.

\section{References}

Atkinson, R. W., Fuller, G. W., Anderson, H. R., Harrison, R. M., \& Armstrong, B. (2010). Urban ambient particle metrics and health: a time-series analysis. Epidemiology, 21(4), 501-511.

Baltagi, Badi H. (2005). Econometric Analysis of Panel Data (3rd ed). New York: John Wiley and Sons. Ltd Pablication.

Baltagi, Badi H. (2008). Econometric Analysis of Panel Data (4th ed). New York John Wiley and Sons. Ltd Pablication.

Brauer, M., Amann, M., Burnett, R. T., Cohen, A., Dentener, F., Ezzati, M., ... Van Donkelaar, A. (2012). Exposure assessment for estimation of the global burden of disease attributable to outdoor air pollution. Environmental science \& technology, 46(2), 652-660.

Brook, R. D., Franklin, B., Cascio, W., Hong, Y., Howard, G., Lipsett, M., ... Tager, I. (2004). Air pollution and cardiovascular disease: a statement for healthcare professionals from the Expert Panel on Population and Prevention Science of the American Heart Association. Circulation, 109(21), 2655-2671.

Cadelis, G., Tourres, R., \& Molinie, J. (2014). Short-term effects of the particulate pollutants contained in Saharan dust on the visits of children to the emergency department due to asthmatic conditions in Guadeloupe (French Archipelago of the Caribbean). PloS one, 9(3), e91136.

Cao, J., Yang, C., Li, J., Chen, R., Chen, B., Gu, D., \& Kan, H. (2011). Association between long-term exposure to outdoor air pollution and mortality in China: a cohort study. Journal of hazardous materials, 186(2-3), 1594-1600.

Chen, X., Shao, S., Tian, Z., Xie, Z., \& Yin, P. (2016). Impacts of air pollution and its spatial spillover effect on public health based on China's big data sample. Journal of Cleaner Production, 142, 915-925.

Correia, A. W., Pope III, C. A., Dockery, D. W., Wang, Y., Ezzati, M., \& Dominici, F. (2013). The effect of air pollution control on life expectancy in the United States: an analysis of 545 US counties for the period 2000 to 2007. Epidemiology (Cambridge, Mass.), 24(1), 23.

Davidson, C. (2003). Marine Notice: Carbon Dioxide: Health Hazard. Australian Maritime Safety Authority.

Dominici, F., Daniels, M., Zeger, S. L., \& Samet, J. M. (2002). Air pollution and mortality: estimating regional and national dose-response relationships. Journal of the American Statistical Association, 97(457), 100-111.

Fang, Y., Naik, V., Horowitz, L. W., \& Mauzerall, D. L. (2013). Air pollution and associated human mortality: the role of air pollutant emissions, climate change and methane concentration increases from the preindustrial period to present. Atmospheric Chemistry and Physics, 13(3), 1377-1394.

Fotourehchi., Z. (2016). Health effects of air pollution: An empirical analysis for developing countries. Atmospheric Pollution Research, 7(1), 201-206. Retrieved from_http://www.who.int/news-room/factsheets/detail/ambient-(outdoor)-air-quality-and-health http://databank.worldbank.org/data/reports 
Kim, K. H., Kabir, E., \& Kabir, S. (2015). A review on the human health impact of airborne particulate matter. Environment international, 74, 136-143.

Kinney, P. L. (2008). Climate change, air quality, and human health. American journal of preventive medicine, 35(5), 459-467.

Krewski, D. (2009). Evaluating the effects of ambient air pollution on life expectancy.

Mann, J. K., Tager, I. B., Lurmann, F., Segal, M., Quesenberry Jr, C. P., Lugg, M. M., ... Van Den Eeden, S. K. (2002). Air pollution and hospital admissions for ischemic heart disease in persons with congestive heart failure or arrhythmia. Environmental Health Perspectives, 110(12), 1247.

Meister, K., Johansson, C., \& Forsberg, B. (2012). Estimated short-term effects of coarse particles on daily mortality in Stockholm, Sweden. Environmental health perspectives, 120(3), 431.

Mukhopadhyay, K., \& Forssell, O. (2005). An empirical investigation of air pollution from fossil fuel combustion and its impact on health in India during 1973-1974 to 1996-1997. Ecological Economics, 55(2), 235-250.

Poloniecki, J. D., Atkinson, R. W., de Leon, A. P., \& Anderson, H. R. (1997). Daily time series for cardiovascular hospital admissions and previous day's air pollution in London, UK. Occupational and environmental medicine, 54(8), 535-540.

Pope III, C. A., Burnett, R. T., Thun, M. J., Calle, E. E., Krewski, D., Ito, K., \& Thurston, G. D. (2002). Lung cancer, cardiopulmonary mortality, and long-term exposure to fine particulate air pollution. Jama, 287(9), $1132-1141$.

Pope, C. A., Burnett, R. T., Thurston, G. D., Thun, M. J., Calle, E. E., Krewski, D., \& Godleski, J. J. (2004). Cardiovascular mortality and long-term exposure to particulate air pollution: epidemiological evidence of general pathophysiological pathways of disease. Circulation, 109(1), 71-77.

Samet, J. M., Dominici, F., Curriero, F. C., Coursac, I., \& Zeger, S. L. (2000). Fine particulate air pollution and mortality in 20 US cities, 1987-1994. New England journal of medicine, 343(24), 1742-1749.

Shah, A. S., Langrish, J. P., Nair, H., McAllister, D. A., Hunter, A. L., Donaldson, K., ... Mills, N. L. (2013). Global association of air pollution and heart failure: a systematic review and meta-analysis. The Lancet, 382(9897), 1039-1048.

\section{Appendix}

Redundant Fixed Effects Tests

Equation: Untitled

Test cross-section fixed effects

\begin{tabular}{lrrr}
\hline \hline Effects Test & Statistic & d.f. & Prob. \\
\hline \hline Cross-section F & 209.244405 & $(29,68)$ & 0.0000 \\
Cross-section Chi-square & 459.248364 & 29 & 0.0000 \\
\hline \hline
\end{tabular}

Correlated Random Effects - Hausman Test

Equation: Untitled

Test cross-section random effects

\begin{tabular}{lrrr}
\hline \hline Test Summary & Chi-Sq. Statistic & Chi-Sq. d.f. & Prob. \\
\hline \hline Cross-section random & 18.264224 & 4 & 0.0011 \\
\hline \hline
\end{tabular}

Dependent Variable: LMORT_M

Method: Panel Least Squares

Date: 07/01/18 Time: 11:25

Sample (adjusted): 20002012

Periods included: 5

Cross-sections included: 30 
Total panel (unbalanced) observations: 102

\begin{tabular}{|c|c|c|c|c|}
\hline Variable & Coefficient & Std. Error & t-Statistic & Prob. \\
\hline LPM2_5 & 0.036441 & 0.051753 & 0.704121 & 0.4838 \\
\hline $\mathrm{LCO} \overline{2}$ & 0.071167 & 0.041822 & 1.701677 & 0.0934 \\
\hline LOTHER_GAS & 0.010897 & 0.001692 & 6.439972 & 0.0000 \\
\hline LSC_M & -0.319606 & 0.021913 & -14.58496 & 0.0000 \\
\hline $\mathrm{C}^{-}$ & 6.567690 & 0.183347 & 35.82110 & 0.0000 \\
\hline \multicolumn{5}{|c|}{ Effects Specification } \\
\hline \multicolumn{5}{|c|}{ Cross-section fixed (dummy variables) } \\
\hline R-squared & 0.852498 & Mean dependent var & & 5.219650 \\
\hline Adjusted R-squared & 0.848857 & S.D. dependent var & & 0.410668 \\
\hline S.E. of regression & 0.043349 & Akaike info criterion & & -3.177843 \\
\hline Sum squared resid & 0.127784 & Schwarz criterion & & -2.302852 \\
\hline Log likelihood & 196.0700 & Hannan-Quinn criter. & & -2.823529 \\
\hline F-statistic & 272.6157 & Durbin-Watson stat & & 0.996592 \\
\hline Prob(F-statistic) & 0.000000 & & & \\
\hline
\end{tabular}

Redundant Fixed Effects Tests

Equation: Untitled

Test cross-section fixed effects

\begin{tabular}{lrrr}
\hline \hline Effects Test & Statistic & d.f. & Prob. \\
\hline \hline Cross-section F & 112.338447 & $(29,68)$ & 0.0000 \\
Cross-section Chi-square & 396.776156 & 29 & 0.0000 \\
\hline \hline
\end{tabular}

Correlated Random Effects - Hausman Test

Equation: Untitled

Test cross-section random effects

\begin{tabular}{lcrr}
\hline \hline Test Summary & Chi-Sq. Statistic & Chi-Sq. d.f. & Prob. \\
\hline \hline Cross-section random & 25.676609 & 4 & 0.0000 \\
\hline \hline
\end{tabular}

Dependent Variable: LMORT_F

Method: Panel Least Squares

Date: 07/01/18 Time: 10:53

Sample (adjusted): 20002012

Periods included: 5

Cross-sections included: 30

Total panel (unbalanced) observations: 102

\begin{tabular}{crrrr}
\hline \hline Variable & Coefficient & Std. Error & t-Statistic & Prob. \\
\hline \hline LPM2_5 & 0.003345 & 0.065160 & 0.051332 & 0.9592 \\
LCO2 & 0.125363 & 0.051682 & 2.425674 & 0.0179 \\
LOTHER_GAS & 0.013620 & 0.002103 & 6.476425 & 0.0000 \\
LSC_F & -0.284615 & 0.025463 & -11.17772 & 0.0000 \\
C & 5.897152 & 0.234283 & 25.17103 & 0.0000 \\
\hline \hline
\end{tabular}

Effects Specification 


\section{Cross-section fixed (dummy variables)}

\begin{tabular}{lllr}
\hline \hline R-squared & 0.798824 & Mean dependent var & 4.607342 \\
Adjusted R-squared & 0.783400 & S.D. dependent var & 0.419554 \\
S.E. of regression & 0.054055 & Akaike info criterion & -2.736416 \\
Sum squared resid & 0.198694 & Schwarz criterion & -1.861425 \\
Log likelihood & 173.5572 & Hannan-Quinn criter. & -2.382102 \\
F-statistic & 182.3159 & Durbin-Watson stat & 0.597123 \\
Prob(F-statistic) & 0.000000 & & \\
\hline \hline
\end{tabular}

\section{Copyrights}

Copyright for this article is retained by the author(s), with first publication rights granted to the journal.

This is an open-access article distributed under the terms and conditions of the Creative Commons Attribution license (http://creativecommons.org/licenses/by/4.0/). 